\title{
Inhomogenous risk exposure in dual insurance system: selection effects in Germany's long-term care plans
}

\section{Thomas Neusius ${ }^{1}$}

Received: 27 April 2020 / Accepted: 5 December 2020 / Published online: 11 January 2021

(c) The Author(s) 2021

\begin{abstract}
Long-term care (LTC) gains attention in ageing societies. Making LTC insurance affordable for the wide public is a primary objective of politics and insurance companies alike. Germany's LTC insurance, introduced 25 years ago, is split in two branches, a private and a public one. The per-capita claims diverge in the two systems. This study is dedicated to explain the difference in average claims seen in the German LTC system. Based on publicly available claims data, we decompose the contributions to the difference in claims and we quantify the advantage gained by the private LTC insurance through selection of low-risk enrollees. Furthermore, the study provides simulation results of the development of the claims' differences over the next 40 years. In order to level off the claims differences, transfer payments from the private to the public LTC insurance have been suggested as a matter of fair risk sharing. However, it turns out that such a payment scheme does not necessarily work in favor of the public system troughout the next 40 years. Therefore, it seems unlikely that such a financial transfer is able to substantially ease the public LTC insurance's financial burden.
\end{abstract}

Keywords Long-term care $\cdot$ Health insurance $\cdot$ Risk adjustment $\cdot$ Pay-as-you-go system

JEL Classification $\mathrm{G} 22 \cdot \mathrm{I} 13 \cdot \mathrm{I} 18$

Supplementary Information The online version of this article (https://doi.org/10.1007/s43546-02000028-3) contains supplementary material, which is available to authorized users.

Thomas Neusius

thomas.neusius@hs-rm.de

1 Wiesbaden Business School, RheinMain University of Applied Sciences, Bleichstr. 44, 65183 Wiesbaden, Germany 


\section{Risk exposure in public and private LTC insurance}

Germany's health insurance is organized in two pillars. The majority of $90 \%$ of the population is covered by the statutory health insurance (SHI), while about $10 \%$ seek coverage from private health insurance (PHI) (Busse and Blümel 2014). In 1995, an obligatory long-term care (LTC) insurance was introduced in addition to the two health insurance branches. The dualism of health insurance was also transferred to the LTC insurance (LTCI), which consists of the statutory (public, non-profit) part (SPV) and the private part (PPV). The PPV carries in 2018 expenditures of 1.4 bn. $€$ (3.3\% of SPV's and PPV's common LTC spending) (Verband der Privaten Krankenversicherung e.V. 2019), compared to 41.3 bn. $€$, funded by SPV (Bundesministerium für Gesundheit (BMG) 2020). The share of the population insured in PPV is 11.2\%. 252 thsd. insurees received benefits, corresponding to $5.9 \%$ of all LTC beneficiaries and to $2.7 \%$ of all PPV enrollees (Bundesministerium für Gesundheit (BMG) 2020).

The entitlements of SPV and PPV are defined uniquely (Harrington et al. 2002; Federal Ministry of Health, Germany 2018). However, the per-capita spending of the two LTC pillars differs considerably.

In the recent past, the entitlements of the LTCI were expanded profoundly, which in turn lead to rising expenditures (Federal Ministry of Health, Germany 2018). Further improvements of the coverage and a more appreciative remuneration of care professionals are discussed and entered the political debate (Rothgang and Kalwitzki 2017; Bundesländer Hamburg, Berlin, Bremen, Schleswig-Holstein 2019). These improvements would require additional financing. Therefore, the spending differences between the public and the private sector attracted political attention. Both, scientists and politicians, proposed to establish a financial transfer between SPV and PPV to equalize the risk exposure (Schulz-Asche 2019; Zimmermann et al. 2019; Rothgang 2018a, b). The proponents of such a transfer mechanism emphasize the insufficient solidarity of the dual setting. They complain about existing inequalities in the risk exposure. However, the general attitude is based on the impression that the private PPV was profiteer of the present regulation.

This analysis addresses the following questions:

1. Which kind of inequalities between the two branches can be found?

2. In how far are selection effects responsible for the differences between the two LTC insurance branches?

3. How can theses selection effects be compensated by transfer payments?

4. How will the transfer payments evolve in the next 40 years, given the democraphic situation of the two branches?

We will discuss the answers to these questions with respect to the political implications.

The risk selection in the German health insurance market has been the subject of several recent publications (Grunow and Nuscheler 2014; Bünnings and 
Tauchmann 2015; Polyakova 2016; Panthöfer 2016). The present analysis extends the discussion to the long-term care sector, which shares some similiarities with the health insurance system, which also is split between public and private providers. It contributes therefore to an ongoning debate about the organization of health and LTC insurance.

\section{Long-term care insurance in Germany}

The German LTCI operationalizes the LTC risk on the basis of five levels (LTC grades). The scoring, which determines the LTC grade, takes various dimensions into account, among them mobility, cognitive abilities, language, behavior, medical condition, and social life. The applicants for LTC benefits are assessed and receive payments depending on the level granted. The benefits do not depend on the individual needs and do not cover the typical expenses entirely. Therefore, people in need of LTC face out-of-pocket payments unless they buy further insurance cover on a private basis. ${ }^{1}$

Whereas the entitlements of SPV and PPV are identical, the financing is organized differently. The SPV is financed in a pay-as-you-go (PAYG) scheme. The premiums charged by the SPV are not based on medical underwriting but on a nationwide community rating. As the premiums are charged as a percentage of gross wage earnings, they are referred to as contributions. In 2020, the contribution rate amounts $3.05 \%$ of wages up to a maximum contribution of $142.97 €$ per month. As the benefits of SPV (and identically of PPV) are uniquely defined, the PAYG financing on the basis of wage-dependent contributions involves various types of redistribution compared to an actuarial approach with risk-adjusted premiums.

- The non-beneficiaries support the enrollees in need of care,

- the high-income enrollees support the low-income enrollees,

- the younger cohorts ${ }^{2}$ support the elderly, which receive essentially the benefits.

In particular, the last point deserves attention. The financial burden in the PAYG system is shared among the younger people, while the benefits are caused in large parts by policy holders above age 75 . Therefore, the contribution rate depends not just only on SPV's benefits but also on the demographic situation. Even with constant entitlements, a varying contribution rate is to be expected as the age distribution shifts towards the elderly.

The statutory health insurance is exposed to competition between the various sickness funds. Therefore, a morbidity-based risk-adjustment scheme is required to contain selection effects (Ven and Ellis 2000). Such a risk-adjustment has been established since 2009 (Busse and Blümel 2014, pp. 39, 245). The sickness funds

\footnotetext{
1 There is a tax-funded assistance for those who cannot afford the out-of-pocket payments.

${ }^{2}$ Here, and in the following, the term cohort is used to refer to a birth cohort, i.e., the enrollees that have a common year of birth.
} 
are also the providers of SPV. In contrast to health plans, there is no competition among the sickness funds in case of LTC plans. As a consequence, instead of riskadjustment, the claims are pooled ex-post. The sickness funds do not compete with respect to future clients in the realm of SPV (Rothgang 2000, p. 429). Therefore, no selection effects are relevant between the SPV's various sickness funds.

In contrast to SPV's PAYG approach, the private PPV is financed in a funded system, similar to private health insurance [see (Hofmann and Browne 2013) for details on the actuarial approach]. The premiums in the PPV are in principle risk adjusted and depend on the age and on individual preexisting conditions at the first inscription to the health plan. Aging provisions are built to ensure affordability of the health plan for the elderly. After inscription, no further risk information influences the premium. Therefore, insurees are not exposed to an individual reclassification risk.

In addition to the risk-adequate pricing, the regulation of PPV installed various mechanisms of redistribution within the PPV, such that there is no strict risk adequacy. In particular, the premiums in PPV are bound by the same threshold as the contributions to SPV, e.g. in 2020, $142.97 €$ per month. Technically, policy holders with a premium above the threshold receive subsidies to keep the effective premium at the cap level. The amount required to afford this capping is raised via a unique fee levied from the insurees, who's premiums are below the threshold (Weber 2010).

$88.8 \%$ of the population are compulsorily covered by the SPV (Bundesministerium für Gesundheit (BMG) 2020). People with high income (in 2020 above 62,550 $€$ p.a.) are free to switch to a private provider. ${ }^{3}$ In addition, civil servants have the option to seek coverage of PPV. In case of civil servants, the option to chose freely between private and statutory LTC plans is strongly influenced by the privilege to receive indemnification payments from the employing authority. This right is forfeited for those civil servants that stay with the statutory system. ${ }^{4}$ Hence, civil servants are in a vast majority covered by PPV. Finally, self-employed people can opt-out from SPV. The limited access to PPV may induce a selective effect, if the requirements for switching from SPV to PPV correlate with LTC risk exposure.

\section{Redistribution between SPV and PPV}

The SPV has implemented two types of redistribution (Arnold and Rothgang 2010). Risks are shared among the insureds, like in any other insurance. Community rating extends the risk sharing beyond the level seen in insurances using medical underwriting.

In addition to risk sharing, people with higher wages pay more fore the same entitlements. That constitutes a redistribution from high- to low-income members.

\footnotetext{
3 The decision is mainly driven by the choice of health insurance plan. LTCI follows, as the application is restricted to the health plan provider.

4 As of January 1, 2020, the federal states Hamburg, Bremen, Thüringen, and Brandenburg have established an alternative payment for civil servants, which stay with the statutory system, Berlin is about to follow, which reduces the incentive to switch to a private plan (Bührer et al. 2018b; Neusius 2017).
} 
It has been argued that a financial transfer between SPV and PPV should also compensate the effects of income-related redistribution (Arnold and Rothgang 2010). Yet, income-induced redistribution is in conflict with the equivalence principle of insurance. Subsidies for low-income members could alternatively be provided on the basis of taxes, as, e.g. in Switzerland or the Netherlands (SVRW - Sachverständigenrat zur Begutachtung der gesamtwirtschaftlichen Entwicklung 2017; Breyer 2018; SVRW - Sachverständigenrat zur Begutachtung der gesamtwirtschaftlichen Entwicklung 2018).

Here, the analysis is not dealing with the compensation of income inequalities. In the following we restrict our discussion to a transfer system that focuses on actuarial aspects, i.e., on differences in the claims. As the entitlements are identical in SPV and PPV, such differences in claims are interpreted as evidence for selection effects.

\section{Identical benefits-disparate expenditures: risk exposure in SPV and PPV}

The per-capita spending of SPV was $525.06 €$ in 2018 (Bundesministerium für Gesundheit (BMG) 2020); in contrast, PPV had an average expenditure of $155.00 €$ per insured (Verband der Privaten Krankenversicherung e.V. 2019). With respect to the identical insurance benefits, this raises the question as to how such a discrepancy can be understood (Neusius 2019).

An important effect is that PPV covers in many cases just a part of the benefits. Civil servants are entitled to receive an indemnification payment ("beamtenrechtliche Beihilfe") directly from their employers, i.e., from the administrative authorities which hired them. Among the PPV insurees above the age 70 , a share ${ }^{5}$ of $62.0 \%$ are partially covered by administrative authorities (BaFin 2019), as seen in Fig. 1. As the LTC risk increases significantly above the age 70, we estimate at least $62.0 \%$ of the PPV beneficiaries are entitled to receive indemnification payments. They receive typically $70 \%$ of their LTC-related benefits from their employers. PPV then covers the $30 \%$ missing to fill the gap to the unique level of LTC payments. Taking this effect into account, the PPV has a per-capita expenditure of $274.75 €$, still far less than SPV by nearly a factor of $2 .^{6}$ The discrepancy remaining can be attributed to a different risk structure in SPV and PPV, that will be further analyzed in the following.

\footnotetext{
5 If the threshold is set to age 75, the percentage raises to $64.6 \%$.

${ }^{6}$ Other analyses estimated a factor of 2.3 (Rothgang and Domhoff 2019). There, a roughly similar level of indemnification, $67 \%$, was assumed. In the present analysis, $70 \%$ was chosen in accordance with the regulation of federal civil servants (Bundesbeihilfeverordnung). A more important discrepancy is the assumption of a share of only $50 \%$ of PPV insurees being entitled to indemnification payments (Rothgang and Domhoff 2019). From the statistics published by the federal agency of financial regulation, BaFin, it can be seen that this underestimates the amount of benefits covered by indemnification (BaFin 2019).
} 

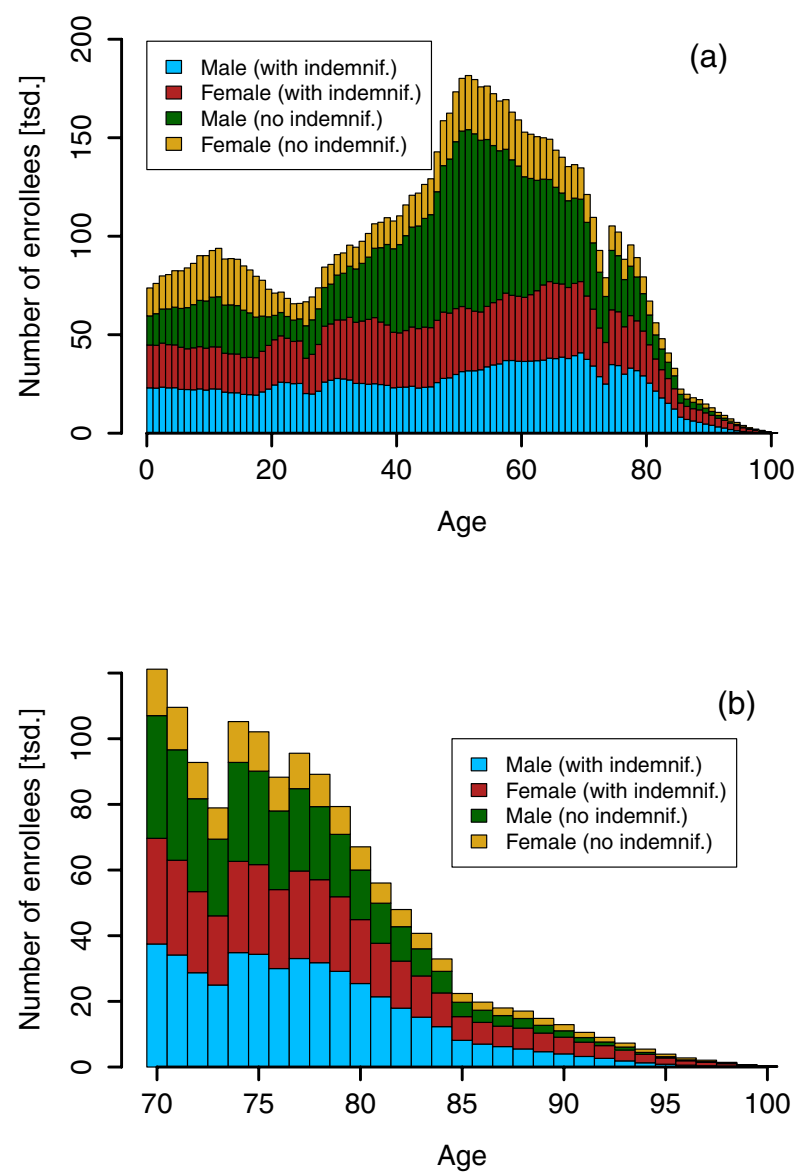

Fig. 1 Age structure of private LTCI (PPV) differentiated according to sex and entitlement to employer indemnification payments. Absolute number of insurees as a function of age in 2018. Source: (BaFin 2019)

\section{Age, sex and claim structure}

The unequal annual per-capita claims in SPV (525.06 €) and PPV $^{7}$ (274.75€) will be attributed to three sources in the present analysis:

1. Different risk exposure in SPV vs. PPV due to age-structure of insurees,

2. different risk exposure in SPV vs. PPV due to sex-ratio of insurees,

3. different risk exposure in SPV vs. PPV due to selection with respect to any other risk driver.

\footnotetext{
${ }^{7}$ Here and in the following, the per-capita claims of PPV include the claims carried by the indemnification system.
} 


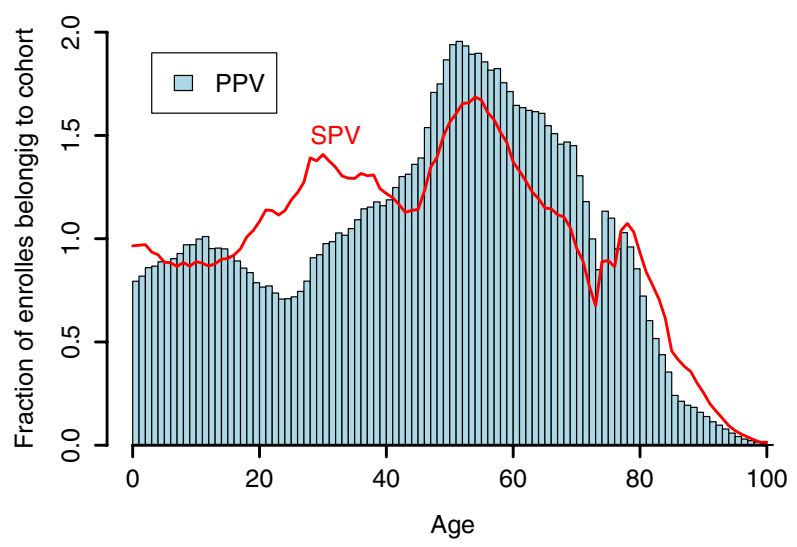

Fig. 2 Age structure of private LTCI (PPV). Share of cohort relative to all insurees in 2018. For comparison, age structure of statutory LTCI (SPV) is also given. Sources: (BaFin 2019; BAS 2020)

The age structure in SPV is considerably different from that of PPV, see Fig. 2. Clearly, that explains some of the differences in the per-capita spending. Presently, the cohorts above the age 80 are under-represented in PPV. In contrast, cohorts born from 1942 through 1977 had an higher-than-average tendency to switch to a private plan. These cohorts are not yet exposed to relevant LTC risk, but they eventually will reach the critical age. In the consequence, PPV will have to carry increasing costs in the years to come (Arnold and Rothgang 2010, 81f).

As can be seen from Fig. 1, men are more likely to switch to the private sector than women. While the sex ratio for civil servants (and other enrollees with entitlement to indemnification payments) is nearly balanced, among the other insurees women are significantly outnumbered.

Age and sex are established risk drivers of health and LTC expenditures. But even the age- and sex-specific claims reveal further differences between SPV and PPV. As the entitlements are identical, the diverging claims are a consequence of the unequal LTC prevalence in the two systems. There are various reasons that may lead to these differences (Rothgang et al. 2013, 85f). Here, we do not decompose the contributions to the prevalence differences. ${ }^{8}$ Instead, we consider the diverging claims as an indicator of selection with respect to health condition. Other analyses found various socio-economic variables correlating with the LTC duration (Guo et al. 2015; Germain et al. 2016; Fuino and Wagner 2020).

The claims of SPV are above those of PPV for all ages up to 80, then the claims of PPV exceed the ones seen in SPV (Fig. 3). Earlier analyses found PPV claims to exceed SPV claims above age 90 (Arnold and Rothgang 2010, p. 80), whereas a direct calculation of LTC prevalences, operationalized as a binary variable (any LTC

\footnotetext{
${ }^{8}$ We compare the LTC risk exposure on the basis of age-specific per-capita claims. As the benefits of SPV and PPV are identical, that is directly linked to LTC prevalence weighted by financial impact. The per-capita claims of PPV are obtained from (BaFin 2019), where the claims are netted of a security margin of $17.8 \%$. The derivation of the SPV's claim structure is laid out in "Supplementary material".
} 


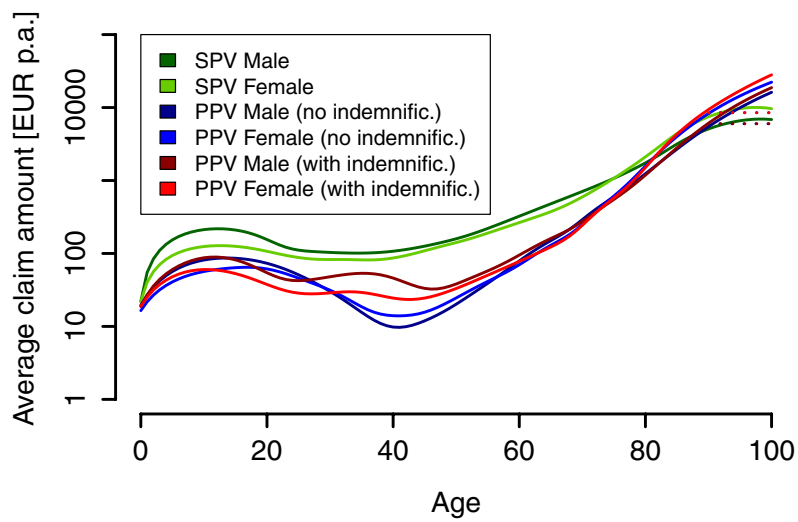

Fig. 3 Age- and sex-specific claim's structure in SPV and PPV (logarithmic scale). For PPV the structure is separately given for insurees receiving indemnification payments from their employer and policy holders that do not receive indemnification payments. The capped claims are indicated by dotted lines on the right. Source: (BaFin 2019; Bundesministerium für Gesundheit (BMG) 2018b, a, 2019a, b, c, d)

grade on/off), found SPV's figures to exceed those of PPV for all ages (Rothgang and Domhoff 2019, p. 18).

It is unclear, whether the steep parts of the PPV's assumed claims above 80 reflect the claims observed or if they are merely rooted in actuarial prudence, i.e., if they reflect high security margins to compensate for the uncertainty of the statistical estimates in these cohorts. Therefore, we performed alternative calculations with capped claims in the PPV. The threshold is chosen such that it reflects approximately the maximum of the SPV claims. The women's claims are capped to a maximum of $8500 €$, the men's claims are capped to a maximum of $6000 €$, see Fig. 3.

\section{Active selection by LTC plans}

The LTC risk exposure in SPV and PPV differs. However, it is less obvious whether this is the consequence of active selection by the private LTC plans. A majority of the German population is mandatorily covered by the SPV. Only a non-representative subset of the population has the option to freely choose between private and statutory plans. However, the switch from the SPV to the PPV is unidirectional in most cases. The return to the statutory system is restrained and in particular policy holders above age 55 can practically not leave the PPV, anymore.

The restrictions of returning back to SPV serve the purpose to suppress cream skimming by the insureds. Enrollees that chose a private plan are supposed to make a final and life-long decision. As a consequence, private LTC plans have to provide a life-long coverage.

Enrollees subscribe to private LTC plans typically when they are younger (Bünnings and Tauchmann 2015). The age-structure of the enrollees of LTC reflects among which cohorts there was a large new business. Selection of specific age groups is therefore not possible in the long run. 
Since December 21, 2012, unisex pricing is compulsory for insurance premiums in new business. In contrast, plans that existed before still retain their sexspecific premiums. It is therefore possible that the sex-ratio in PPV results to some degree from the former discrimination between men and women. Analyses of panel data revealed a higher probability of men to switch to a private plan among the individuals with access to both systems (Bünnings and Tauchmann 2015). There is also evidence that the unisex mandate reduced the probability of men switching to a private plan relative to the probability of women. That was interpreted as a reduction of sex related risk segmentation (Huang and Salm 2020).

Whatever the reasons for the sex imbalance in PPV, there are no direct handles to make LTC plans more attractive for men. In contrast, from an actuarial perspective, unisex pricing makes female contracts relatively more competitive than male contracts.

Like in case of the SPV, a direct selection of risks on the basis of medical underwriting is not permitted as LTC plans do not have the right to reject applicants (Arnold and Rothgang 2010).

\section{Indirect selection effects}

Typically, the LTC plan depends on the choice of the corresponding health plan. In contrast to LTCI, private health plans can reject applications and submit applicants to health assessments upon application. This form of medical underwriting allows private health plans to differentiate premiums according to the expected claims. As a result, individuals with favorable medical conditions are more inclined to opt-out from the statutory system and buy private health coverage (Bünnings and Tauchmann 2015; Bührer et al. 2018a, b). Yet, the precise extent of advantageous selection in private health plans remains disputed (Polyakova 2016; Grunow and Nuscheler 2014).

Indirectly, medical underwriting in the area of private health plans also affects the access to private LTC plans. Therefore, selection effects may eradiate onto the PPV. It is worth noting that selection advantages in private health plans fade out within the first few years (Deutsche Aktuarvereinigung 2014). Figure 3 exhibits such an effect: around the age 40, PPV enrollees without indemnification payments have lower expected claims than PPV enrollees with indemnification payments. The latter are civil servants which chose almost entirely private plans; the switch to private plans is beneficial for them, independent of the individual health condition, whereas applicants without indemnification may hesitate to chose a private plan when confronted with a high premium surcharge upon risk assessment.

As applicants to private health insurance are typically far younger than the LTC relevant age (Bünnings and Tauchmann 2015), the impact of the health plan's medical underwriting onto the LTC risk is difficult to assess. The significant time 
lag of typically 30 years or more makes risk assessment in the case of LTC particularly challenging.

The degrees of freedom for a direct selection of risks are few in PPV. Indirectly, however, selection may occur as a consequence of the restricted access to private health and LTC plans. Three populations are eligible for private plans:

1. civil servants,

2. self-employed people, and

3. employees with gross wage earnings above the predefined threshold.

These groups differ in various aspects from the average population. The specific features of the three populations may correlate with LTC risk exposure. Hence, regulation-induced selection may be relevant for the claim's structure in PPV. Effectively, PPV exhibits in most - and maybe all - ages claims that are below the SPV level, see Fig. 3, also (Rothgang et al. 2017, p. 107).

Selection effects with respect to sex can arise from the income triggered access to PPV. Men earn on average higher gross wages (Statistisches Bundesamt 2018). Therefore a higher share of men are enabled to switch to a private plan. The latter is in line with the much higher percentage of men who chose to stay in statutory plans, although they have access to private plans (so-called voluntary SHI members). ${ }^{9}$

The deviation of PPV's age structure from national figures emerges from the cohort-specific new business. The likelihood to switch to a private health/LTC plan depends on the age of the applicant, i.e.. below the age of 40 the probability to switch to a private plan is higher than in later years (Bünnings and Tauchmann 2015).

\section{How to deal with discrepancies in risk exposure?}

Although the reasons for the discrepancies in the LTC risk exposure remain partially unclear, SPV and PPV do not carry identical risks. This statement is true, even if age- and sex-structure is taken into account. It remains unclear, whether this is uniquely in favor of PPV or not, c.f. Fig. 3. Earlier analysis found only for higher ages a disadvantageous claim structure of PPV (Arnold and Rothgang 2010; Rothgang 2015).

These age levels are relevant for the overall expenditures of PPV, as the life expectancy of the PPV enrollees is higher than for the average population (zur Nieden and Altis 2017; Gartmann 2004; Luy et al. 2015). It is therefore a priory unclear, whether risk exposure works in favor of PPV, as is often claimed (Zimmermann et al. 2019; Schulz-Asche 2019; Greß 2019; Rothgang 2018a).

\footnotetext{
9 The statistics of paying members in the statutory health insurance (SHI) discriminates between such members that have the option to chose a private health plan and those that have not (BMG KM6 2018). The members of SHI with access to private health plans are supposed to acquire the switching option predominantly due to a high income as employee.
} 
The existing inequalities between SPV and PPV are not primarily caused by active selection. Therefore, they do not arise from economical incentives. Hence, a risk-adjustment scheme is unlikely to reduce the selection effects. Mainly, the restricted eligibility to private LTC plans causes heterogeneous populations enrolled in the two branches. However, the regulation-induced selection distorts the competition and it can be argued that there is need for a compensation.

The most elementary effect is the difference in the age- and sex-specific claims, as it clearly constitutes a lower risk exposure of PPV, beyond age and sex dependency. A transfer between SPV and PPV could be devised to level off just the differences in age- and sex-specific claims.

A somewhat broader approach could also include the different claims for men and women in the equalization mechanism. That would compensate for the unbalanced sex ratio. Again, Fig. 3 exhibits a claim structure where female claims are above male claims up to age 75 . Around that age, men cause higher expenses and it is not obvious whether a higher share of female enrollees leads always to higher expenditures.

The most comprehensive transfer approach would also include an equalization of the age structure. Such an equalization is consistent with SPV's PAYG approach but alien to the funded financing in PPV. In the next section, we describe, how these three transfer mechanisms can be implemented.

\section{Risk-adjustment-technical approach}

Risk adjustment is typically implemented to offset unintended selection incentives among health plans, when strict risk-adjusted premiums are absent (Ven and Ellis 2000). In the case of German LTCI, selection effects may work to the advantage or disadvantage of PPV against SPV.

Risk equalization between PPV ${ }^{10}$ and SPV can be rationalized as a consequence of the above mentioned selection effects. In the following we look at three possible approaches for risk equalization.

1. For each age $x$ and each sex, LTC expenses are equalized between SPV and PPV.

2. For each age $x$, LTC expenses are equalized between SPV and PPV and between men and women.

3. SPV and PPV pool their expenses entirely. Each part has to cover the expenses in proportion to the number of insureds, independent of the enrollees' age and sex.

The first approach corresponds to an equalization that just focuses on selection effects with respect to medical conditions. The age- and sex-specificity of LTC expenses is not entering the calculation of transfer payments.

\footnotetext{
${ }^{10}$ Here, we subsume the indemnity payments to PPV. In practice, PPV and the employers of civil servants were asked to find an agreement how to share the amount transferred to the SPV.
} 
The second approach equalizes the selection effects with respect to medical condition and sex. That can be seen as a compensation for the unintended sex-specific selection that is likely to follow from to the legal restrictions of the access to PPV.

The third approach equalizes selection along medical condition, sex and age. It more or less forces the PPV to join in SPV's PAYG scheme, as a redistribution along the cohorts would also embrace the PPV enrollees.

All three approaches are thought of as ex post equalization. The actual expenditure in both systems would be entangled with the expenditure in the other pillar. Hence, that would also force the PPV to revise the actuarial model, as the future expenses would no longer depend on the claim structure of the PPV enrollees and their life expectancy alone, but also on the age and claim structure of the entire LTCI (both branches united).

The ex post compensation of real expenditures would dilute the incentive for cost effectiveness. Alternatively, the transfer could be arranged on the basis of prospective values to overcome this problem. The present analysis will not further discuss such an approach. However, apart from the dualism of PPV and SPV, there is no competition on the LTCI market, as both PPV and SPV manage the corresponding risk without competing (Rothgang 2015); both have each one common risk pool (Sachverständigenrat Gesundheit (Advisory Council on the Assessment of Developments in the Health Care System) 2005, p. 47).

In what follows, the risk drivers of LTC expenses are sex $g \in\{m, w\}$ and age $x \in\{0,1,2, \ldots\}$. The claim amount per risk, $K_{g, x}^{i}$, depends on $g$ and $x$. It potentially differs between the enrollees of SPV and of PPV, indicated in the claims amount by the superscript $i \in\{\mathrm{spv}, \mathrm{ppv}\}$.

The number of enrollees is given as $n_{g, x}^{i}$. The total expenditures $E$ can then be obtained as

$$
\begin{aligned}
E^{\mathrm{spv}} & =\sum_{x, g} n_{g, x}^{\mathrm{spv}} \cdot K_{g, x}^{\mathrm{spv}}, \\
E^{\mathrm{ppv}} & =\sum_{x, g} n_{g, x}^{\mathrm{ppv}} \cdot K_{g, x}^{\mathrm{ppv}}, \\
E & =E^{\mathrm{spv}}+E^{\mathrm{ppv}} .
\end{aligned}
$$

\section{Age- and sex-specific risk equalization}

The average claim amount over both branches is

$$
\bar{K}_{g, x}=\frac{n_{g, x}^{\mathrm{spv}} \cdot K_{g, x}^{\mathrm{spv}}+n_{g, x}^{\mathrm{ppv}} \cdot K_{g, x}^{\mathrm{ppv}}}{n_{g, x}^{\mathrm{spv}}+n_{g, x}^{\mathrm{ppv}}},
$$

as long as differences in age and sex structure are not subject of the transfer. Here, we refer to the quantities of such an approach with the superscript as. Virtually, in 
this approach every system is charged with the above average claim amount, such that both branches carry the following expenses

$$
\begin{aligned}
& E^{\mathrm{spv}, a s}=\sum_{x, g} n_{g, x}^{\mathrm{spv}} \cdot \bar{K}_{g, x}, \\
& E^{\mathrm{ppv}, a s}=\sum_{x, g} n_{g, x}^{\mathrm{ppv}} \cdot \bar{K}_{g, x} .
\end{aligned}
$$

The transfer from PPV to SPV reads then

$$
E^{\text {trans,as }}=E^{\mathrm{ppv}, a s}-E^{\mathrm{ppv}} .
$$

\section{Age-specific risk equalization}

The average claim amount over both branches and both sexes is

$$
\bar{K}_{x}=\frac{n_{m, x}^{\mathrm{spv}} \cdot K_{m, x}^{\mathrm{spv}}+n_{w, x}^{\mathrm{spv}} \cdot K_{w, x}^{\mathrm{spv}}+n_{m, x}^{\mathrm{ppv}} \cdot K_{m, x}^{\mathrm{ppv}}+n_{w, x}^{\mathrm{ppv}} \cdot K_{w, x}^{\mathrm{ppv}}}{n_{m, x}^{\mathrm{spv}}+n_{w, x}^{\mathrm{spv}}+n_{m, x}^{\mathrm{ppv}}+n_{w, x}^{\mathrm{ppv}}},
$$

as long as age structure is not subject of the transfer approach. The quantities obtained in such a transfer approach are referred to using the superscript $a$. Virtually, every system is charged with the above average claim amount, such that both branches pay for the following expenses

$$
\begin{aligned}
& E^{\mathrm{spv}, a}=\sum_{x, g} n_{g, x}^{\mathrm{spv}} \cdot \bar{K}_{x}, \\
& E^{\mathrm{ppv}, a}=\sum_{x, g} n_{g, x}^{\mathrm{ppv}} \cdot \bar{K}_{x} .
\end{aligned}
$$

The transfer is then organized in such a way, that it charges the PPV with the following additional amount

$$
E^{\mathrm{trans}, a}=E^{\mathrm{ppv}, a}-E^{\mathrm{ppv}} .
$$

\section{Complete pooling of risks}

The average claim amount per enrollee reads

$$
\bar{K}=\frac{E}{n},
$$


with $n=\sum_{g, x}\left(n_{g, x}^{\mathrm{spv}}+n_{g, x}^{\mathrm{ppv}}\right)$ being the sum of people covered by both branches of LTCI. We refer to the quantities obtained in the complete pooling approach using the superscript $t$.

From the number of enrollees, the expenses can be obtained, which correspond to the average claim

$$
\begin{aligned}
& E^{\mathrm{spv}, t}=\bar{K} \cdot \sum_{x, g} n_{g, x}^{\mathrm{spv}}, \\
& E^{\mathrm{ppv}, t}=\bar{K} \cdot \sum_{x, g} n_{g, x}^{\mathrm{ppv}} .
\end{aligned}
$$

The transfer charges the PPV with a payment of

$$
E^{\mathrm{trans}, t}=E^{\mathrm{ppv}, t}-E^{\mathrm{ppv}} .
$$

As a result, both branches are confronted with average claims independent of the varying risk structure in the two branches.

For the figures of 2018, i.e., claims data and age structure allow to determine the transfer amounts.

$$
\begin{aligned}
& E^{\text {trans, }, t}=1.86 \text { bn. } € \\
& E^{\text {trans }, a}=1.17 \text { bn. } € \\
& E^{\text {trans,as }}=0.92 \text { bn. } €
\end{aligned}
$$

In 2018 an amount of 1.23 bn. $€$ corresponds to $0.1 \%$-points of SPV's gross wagerelated contribution rate. The maximum effect to the contribution rate of SPV would be a relief of $0.15 \%$-points ${ }^{11}$ (Neusius 2019). Therefore, even a complete pooling of LTC expenditures between SPV and PPV would not permit a substantial easement for the statutory system. Proposals of transfer payments between SPV and PPV most often include additionally a component based on the income redistribution (Zimmermann et al. 2019; Schulz-Asche 2019; Rothgang 2018a, b). As the overall effect of the risk based component, as discussed here, is minor, such prosals essentially consist in a tax-like redistribution of wages or fail to be relevant for SPV's contribution rate.

\section{Transfer between PPV and SPV_-development over time}

The figures given in Eqs. (16)-(18) are just a snapshot. Depending on the increase in expenditure, the risk structure of the populations and primarily on the demographic dynamics, the transfer amount will change in the future. In the present analysis, a

11 The last increase of the contribution rate took effect as of Jan 1, 2019 with an increase of 0.5\%-pts. 
simulation has been performed of the time evolution of the transfer between PPV and SPV.

To perform such a simulation, some assumptions are required about the time evolution of

1. age- and sex-structure of the populations under risk and

2. age- and sex-specific per-capita claims.

We address both point in the next two sections.

\section{Simulation model}

The simulation of the future age- and sex-structure requires a model of the demographic dynamics of the populations in both, SPV and PPV. These dynamics are determined by mortality, new business from outside (like newborns), migration patterns (immigration and emigration), and by the switching between the two systems.

The core of the simulation is a cohort-component model (Smith et al. 2002) to project the future populations of enrollees in both, PPV and SPV. The populations of both systems, SPV and PPV are to be determined. Due to characteristics in the life expectancy, we consider the PPV as divided in two subpopulations, the public servants entitled to receive indemnification payments (ppv-b) and the other insurees without such an entitlement (ppv-n). Hence, there are three populations, $i \in\{\mathrm{spv} ; \mathrm{ppv}-\mathrm{b}, \mathrm{ppv}-\mathrm{n}\}$, the cohorts of which are to be calculated along the dimensions sex $g \in\{m, w\}$ and age $x \in\{0 ; 1 ; 2 ; \ldots\}$ and in time $\tau \in\{2018, \ldots, 2060\}$. We chose the simulation time $t$ such that $t=0$ corresponds to $\tau=2018$. In year $t$, the mortality per year of a person with sex $g$, aged $x$, and insured in system $i$ is referred to as $q_{g ; x}^{i}(t)$. The number of enrolles is then denoted by $n_{g ; x}^{i}(t)$. The gain of enrollees of age $x$ and sex $g$ in year $t$ and system $i$, including any person that has not been enrolled in the previous year, is represented by the term $m_{g ; x}^{i}(t)$. In principle, this number can be both positive or negative, as it accounts also for lapsation of existing contracts. The development of the cohorts in each system is then given by

$$
\begin{gathered}
n_{g ; x+1}^{i}(t+1)=n_{g ; x}^{i}(t) \cdot\left[1-q_{g ; x}^{i}(t)\right]+m_{g ; x+1}^{i}(t+1) \quad \text { for } x>0, \\
n_{g ; 0}^{i}(t+1)=m_{g ; 0}^{i}(t+1) .
\end{gathered}
$$

Once the populations are determined for all $t=0,1,2, \ldots, 42$, the expenditures can easily be obtained analogously to Eqs. (1) and (2). The transfer mechanism follows then as laid out in Eqs. (7), (11), and (15).

\section{Assumptions and input data}

The initial population of SPV is determined from (BAS 2020), of PPV from (BaFin 2019). The dynamics are driven by mortality rates and cohort gains. 
Table 1 Assumptions for the life expectancy

Table 2 Adjustment factors according to the values in Table 1
Remaining life expectancy at $x=65$

\begin{tabular}{llllll}
\hline & $\mathrm{w}$ & & $\mathrm{m}$ & \\
\cline { 2 - 3 } \cline { 5 - 6 } & $\mathrm{LE}_{w, 65}^{i}$ & Excess LE & & $\mathrm{LE}_{m, 65}^{i}$ & Excess LE \\
\hline General & 21.0 & 0.0 & & 17.9 & 0.0 \\
$\begin{array}{l}\text { PPV with } \\
\begin{array}{l}\text { indemnifica- } \\
\text { tion ppv-b }\end{array}\end{array}$ & 22.7 & 1.7 & & 19.9 & 2.0 \\
$\begin{array}{l}\text { PPV without } \\
\text { indemnifica- } \\
\text { tion ppv-n }\end{array}$ & 22.7 & 1.7 & & \\
\hline
\end{tabular}

Values are based on (Statistisches Bundesamt 2019); mortality is decreased to adjust to the excess life expectancy of major subpopulations in PPV as reported in (Luy et al. 2015; zur Nieden and Altis 2017)

\begin{tabular}{lll}
\hline Adjustment factors & & \\
\hline$i$ & $\varphi_{w}^{i}$ & $\varphi_{m}^{i}$ \\
\hline PPV with indemnification ppv-b & 0.79 & 0.76 \\
PPV without indemnification & 0.79 & 0.88 \\
ppv-n & & \\
\hline
\end{tabular}

The general life table for Germany is used (Statistisches Bundesamt 2019), the annual mortality probability of age $x$ is referred to as $q_{g, x}^{g e r}$. This table is used for the SPV, i.e., $q_{g, x}^{\mathrm{spv}}=q_{g, x}^{g e r}$. There is empirical evidence that civil servants have a higher life expectancy than the average population (zur Nieden and Altis 2017). The same is found in general for the insurees of private health insurance and applies therefore, subsequently, also to the PPV (Gartmann 2004). For public servants, representing the vast majority of the subpopulation $p p v-b$, the expectation value of the remaining life span at age $x=65$ is 2.0 years above the general population for men and 1.7 years for women (zur Nieden and Altis 2017). The subpopulation ppv-n is predominantly formed by self-employed and high-income employed individuals. For self-employed, an excess life expectancy of 0.9 for men and 1.7 years for women was reported (Luy et al. 2015). The excess life expectancy of high-income employees was seen in a range of 0.7 (third income quartile) to 1.4 (forth income quartile) for men and 1.6-1.7 for women (Luy et al. 2015). For the subpopulation ppv-n the mortality will be adjusted such that the life expectancy at age 65 is 1.7 and 0.9 years above the level of the general public for women and men, respectively. 
To imitate this longer life expectancy, we homogeneously decrease the annual mortality rate in age $x$ from (Statistisches Bundesamt 2019), i.e., the value $q_{g, x}^{\text {ger }}$, by a unique factor in such a way that the difference in life expectancy that is reported in Table 1 is reproduced ${ }^{12}$, i.e.,

$$
q_{g, x}^{i}=\varphi_{g}^{i} \cdot q_{g, x}^{g e r}
$$

In order to calculate the life expectancy from the life table $q_{g, x}^{i}$, the cohorts of a model population with $l_{g, x}^{i}$ are determined from

$$
\begin{gathered}
l_{g, 0}^{i}=1,000,000 \\
l_{g, x+1}^{i}=l_{g, x}^{i} \cdot\left(1-q_{g, x}^{i}\right) .
\end{gathered}
$$

The expectation value of the remaining life span at age $x$ is then calculated as

$$
\mathrm{LE}_{g, x}^{i}=\frac{1}{l_{g, x}^{i}} \sum_{k=x} l_{g, k}^{i}-\frac{1}{2} .
$$

The adjustment factor in Eq. (21) is chosen such that the corresponding values of $\mathrm{LE}_{g, 65}^{i}$ fit to the values in Table 1, the results can be seen in Table 2. Our standard scenario is based on a simple assumption, namely that the populations are running off, without any new business or switching, i.e., that $m_{g ; x}^{i}(t)=0$ in Eqs. (19) and (20). That seems a bold simplification, but as the time evolution is simulated up to 2060, the youngest birth cohort that reaches at least an age of 75 is born in 1985. As LTC risk is mainly caused by insurees above age 75 , such that the run-off assumption effectively does not influence the estimates of the expenditures in the years up to 2060. As far as the transfer mechanism is age-specific, the population in the cohorts without relevant LTC risk is entirely negligible for the transfer amount. In case of the complete pooling, the transfer is based on the average claim. Here, the total number of insurees builds the denominator. Sensitivity analysis reveals that in this case, assumptions on the number of newborns may affect the transfer amount. However, as long as the assumptions on newborns are chosen symmetrically between SPV and PPV, the results are essentially identical to the run-off scenario (c.f. Supplementary material, Fig. 7). If for one of the two systems a systematically higher total fertility rate (TFR) is assumed, the transfer amount shifts in favor of the system with lower TFR. See Supplementary material, Figs. 8 and 9 for more details.

In the recent past, the switching between PPV and SPV was nearly balanced out (Neusius et al. 2019). It is unclear, if there will be any changes in the switching behavior. Therefore the assumption that switching is not a relevant effect seems plausible.

\footnotetext{
12 There is a life table for the private health insurance, (PKV-Verband 2017). However, this is an actuarial table including security margins. Therefore, it has a different character than the general life table.
} 


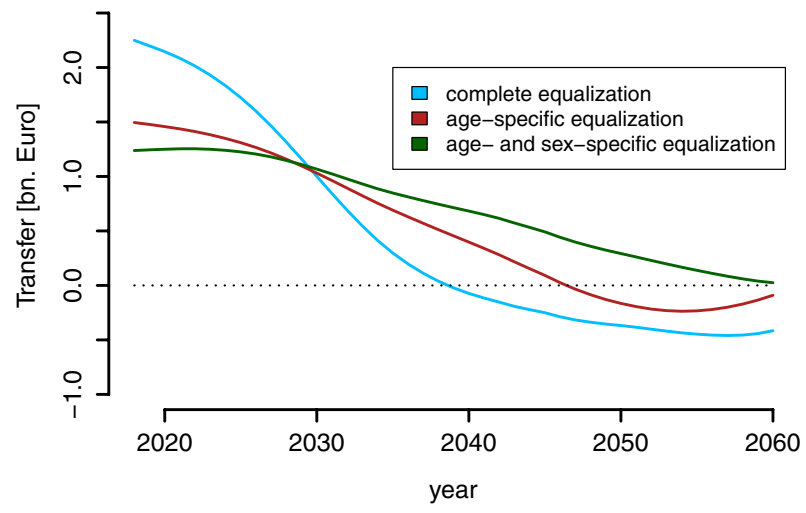

Fig. 4 Transfer from PPV to SPV. In 2018, all types of equalization work in favor of SPV (positive transfer amount). The complete equalization will lead from 2039 to a transfer from SPV to PPV (negative transfer amount). The age-specific transfer will turn against the SPV from 2047 on. And the sex- and age-specific transfer will work in favor of SPV throughout the simulation period. Source: Own calculations, see text

The basis for calculating the claims from the population simulation is Eqs. (1) and (2), which is applied to the subpopulations ppv-b and ppv-n analogously. The claims data of SPV is from (Bundesministerium für Gesundheit (BMG) 2018b, a, 2019a, b, c, d) and in case of PPV from (BaFin 2019). Concerning the claims' structure in the future, it is simply assumed, that per-capita claims will not change over time. That is certainly an unrealistic assumption. However, as the entitlements are identical for SPV and PPV, there is a priori no reason to assume that the claim structures will change relative to each other. A clear trend in the time evolution of prevalence rates could not be found (Rothgang et al. 2017, 109ff). In case that there is just an overall trend in the claims-like inflation-that would change the absolute numbers but the underlying dynamics would not be affected.

\section{Results}

Under the above mentioned assumptions, the time evolution of the transfer between SPV and PPV can be obtained, see Fig. 4. All transfer mechanisms work initially in favor of SPV. As expected, an equalization across the two branches that includes sex and age leads to the largest compensation payment. If the transfer is age-specific, a considerable part of the risk differences disappears, the payments to SPV reduce. As of 2018, sex equalization has just a minor effect, such that a transfer mechanism which is restricted on claims differences that can not be accounted for by sex and age, leads to the lowest transfer amount from PPV to SPV.

The time evolution of all three approaches reveals that the present disadvantage in the SPV's risk structure will shift in the future. Two of the three transfer mechanisms are going to switch sign. The sex- and age-specific approach decreases but stays positive. Overall, it is the only transfer mechanism that is entirely in favor of the SPV. 

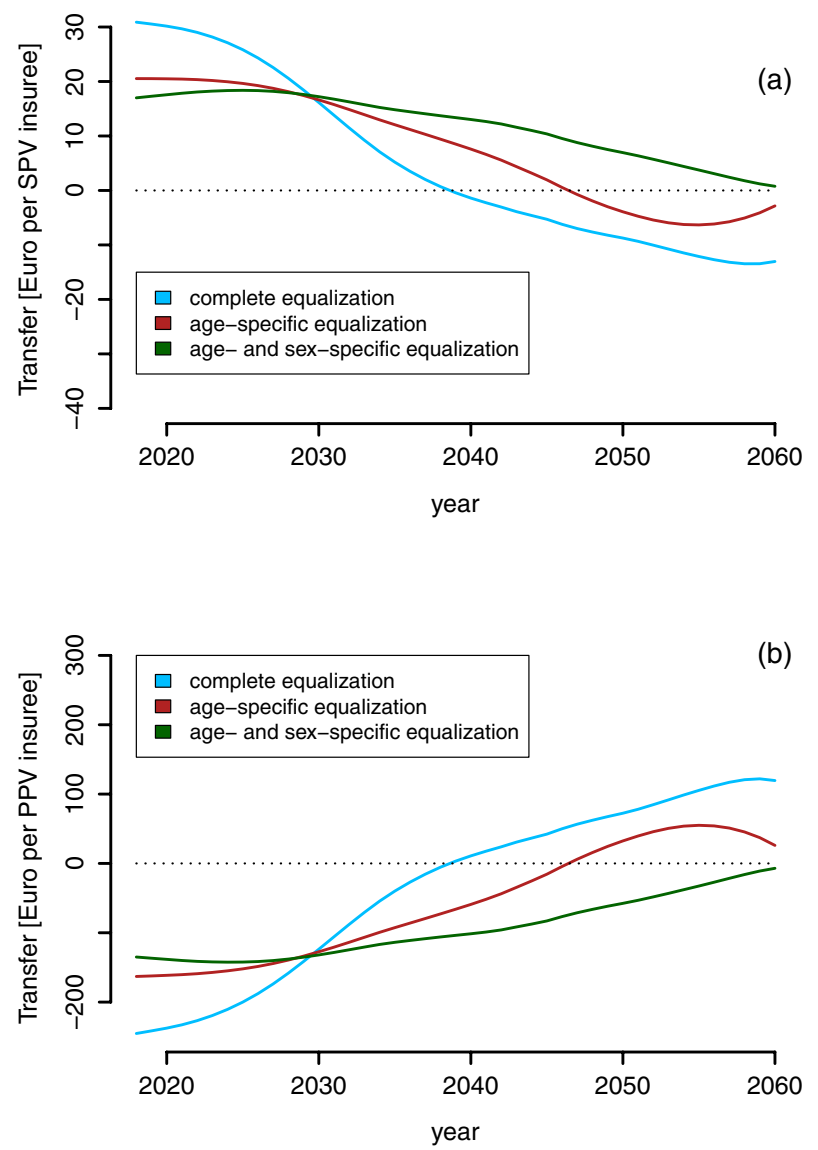

Fig. 5 Transfer from PPV to SPV, expressed as annual amount per enrollee. As the population of PPV enrollees is far smaller, the per-capita figures are much more significant from the PPV perspective than from the SPV perspective. Source: Own calculations, see text

The age-specific risk equalization (compensation for unequal sex-ratios) is in 2018 slightly more advantageous for SPV compared to the sex-specific transfer. It will become negative from 2047 on and exhibits a maximum transfer from SPV to PPV of 0.24 billion $€$.

As expected, the full equalization is in 2018 the most advantageous approach, seen from SPV. But this transfer arrangement will become negative in 2039—-sooner than any other mechanism. That is the consequence of the age structure, which causes presently a considerable disadvantage of SPV, which would be set off by a large transfer amount. But this disadvantage will disappear within the next 15 years, when the age structure will weigh heavily on PPV.

It is noteworthy that the initial transfer from PPV to SPV brings only a very moderate easing for the SPV's enrollees, as these a far more than the PPV's enrollees. In 


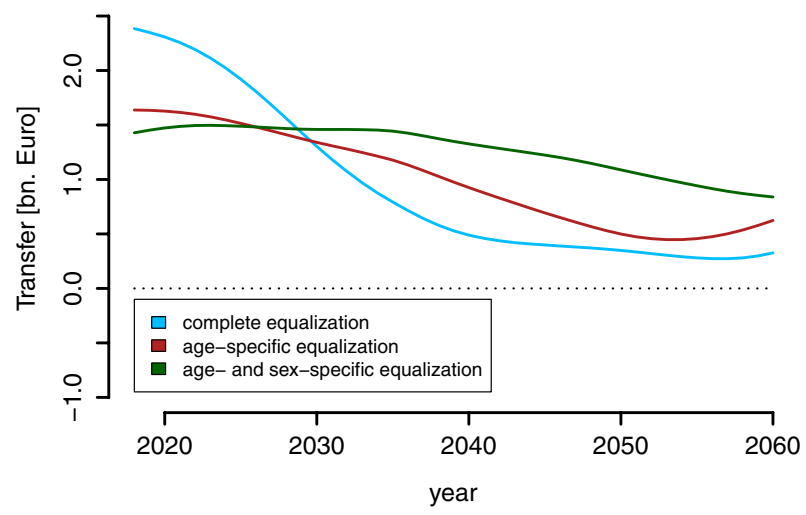

Fig. 6 Transfer from PPV to SPV when per-capita claims are capped. In 2018, all types of equalization work in favor of SPV (positive transfer amount). With the removal of the higher claims, all transfer mechanisms lead to a positive transfer amount throughout the simulation period. However, the complete equalization quickly shrinks to low values, while the age- and sex-specific transfer scheme exhibits only a moderate decrease. That indicates the selection disadvantage of SPV, as in the capped claims profile, PPV exhibits more favorable risks in all ages. Source: Own calculations, see text

contrast, the latter would benefit considerably from the later transfer from SPV to PPV. That can be seen from the per-capita amounts of the transfer, cf. Fig. 5.

It turns out that the overall pattern is robust even when the per-capita claims are capped as laid out above (men's claims capped at $6000 €$, women's claims capped at $8500 €)$. Fig. 6 exhibits a clearly decreasing transfer amount in case of the agespecific and the complete equalization scheme. In contrast, the age- and sex-specific transfer remains roughly constant. None of the approaches with capped claims exhibits an inversion, i.e., a transfer from SPV to PPV.

\section{Political implications}

It was argued that the financial transfer between SPV and PPV was a matter of fairness (Arnold and Rothgang 2010). From an actuarial point of view, the differences in the LTC risk could justify equalization mechanisms. Age is a risk factor that is for SPV and PPV similarly relevant. An equalization of age differences is alien to a LTC insurance on the basis of life-long contracts. Therefore, such a risk factor should not be included in a proper transfer mechanism. Although sex-specific selection effects are caused mainly by regulation of access to private LTC plans, it could constitute a reason for sharing the risks between the sexes. The most obvious dimension of risk equalization is the compensation of differences in risk exposure that remain, once age and sex have been accounted for. The actual choice, which kind of selection effects should be balanced out by a transfer mechanism, is a political decision.

The main concern of the proponents of a risk transfer is a kind of cream skimming of the PPV at the expense of SPV (Schulz-Asche 2019; Zimmermann et al. 2019; 
Greß 2019; Rothgang 2018a, b). In contrast to the common view that the PPV was successful in avoiding the high risk cases in LTC, a closer look reveals, that the LTC risk exposure in PPV may be higher above the age 80 and that enrollees of PPV have a higher life expectancy. These two factors contribute a substantial part to the overall LTC risk. Therefore, various risk equalization approaches work only for the recent future in favor of SPV. But, in the long run, PPV has indeed to carry higher LTC risks. That may justify a compensation payment, i.e., a subsidy from SPV to PPV.

When the per-capita claims of PPV are capped to the SPV's maximum values, the transfer mechanisms indicate higher risks in SPV. However, the transfer amount reduces to values, which can be considered irrelevant for SPV's financing.

In the aftermath of recently enlarged entitlements and the connected hike in LTC expenditures the possibility of a transfer from SPV to PPV was proposed as a way to mitigate further rises in SPV's contribution rate (Schulz-Asche 2019; Zimmermann et al. 2019; Rothgang 2018a, b). The mitigating effect of such a transfer is low, as was seen above, unless further income-based redistribution is included.

In the political debate, the expectation is expressed that there are substantial inequalities between SPV's and PPV's risk exposure. Such inequalities have been found in the present analysis. In contrast to public assessment, the inequalities seen on the basis of the above mentioned statistics are not uniquely advantageous for PPV. However, it remains opaque in how far the higher risk exposure seen in the claim structure corresponds to an empirically higher prevalence or is instead an artefact of actuarial prudence.

A transfer mechanism could contribute to pool risks between SPV and PPV, but it is not realistic to consider such a mechanism to be a substantial effect in keeping the SVP's contribution rate affordable.

Acknowledgements The author thanks the participants of the X. Workshop on Allocation and Distribution in Health of the German Health Economics Society (DGGÖ), held at the University of Constance in November 2019 for their valuable feedback.

Funding Open Access funding enabled and organized by Projekt DEAL.

Data availability All sources of data are publicly available.

Code availability $\mathrm{R}$ scripts can be made available upon request.

\section{Compliance with ethical standards}

Conflict of interest The authors declare no competing interest.

Open Access This article is licensed under a Creative Commons Attribution 4.0 International License, which permits use, sharing, adaptation, distribution and reproduction in any medium or format, as long as you give appropriate credit to the original author(s) and the source, provide a link to the Creative Commons licence, and indicate if changes were made. The images or other third party material in this article are included in the article's Creative Commons licence, unless indicated otherwise in a credit line to the material. If material is not included in the article's Creative Commons licence and your intended use is not permitted by statutory regulation or exceeds the permitted use, you will need to obtain permission directly from the copyright holder. To view a copy of this licence, visit http://creativecommons.org/licen ses/by/4.0/. 


\section{References}

Arnold R, Rothgang H (2010) Finanzausgleich zwischen Sozialer Pflegeversicherung und Privater Pflegeversicherung. In: Göpffarth D, Greß S, Jacobs K, Wasem J (eds) Jahrbuch Risikostrukturausgleich 2009/2010. Von der Selektion zur Manipulation?. Medhochzwei, Heidelberg, pp 65-94

BaFin (2019). Wahrscheinlichkeitstafeln PKV 2018. https://www.bafin.de/SharedDocs/Downloads/DE/ Anlage/dl_wahrscheinlichkeitstafeln_PKV_2018_va.zip. Accessed 03 Jul 2020

BAS (2020) GKV-Ausgabenprofile nach Alter, Geschlecht und Hauptleistungsbereichen, 1996-2018 (Stand: 15.01.2020). https://www.bundesamtsozialesicherung.de/fileadmin/redaktion/Risikostru kturausgleich/Datenzusammenstellung_und_Auswertung/20200401GKV_Altersausgabenprofil e_1996-2018_20200115. xlsx. Accessed 04 Oct 2020

BMG KM6 (2018) Statistik über Versicherte, gegliedert nach Status, Alter, Wohnort und Kassenart (Stichtag: 1. Juli des jeweiligen Jahres). https://www.bundesgesundheitsministerium.de/fileadmin/ Dateien/3_Downloads/Statistiken/GKV/Mitglieder_Versicherte/KM6_2018.xlsx. Accessed 04 Oct 2020

Breyer F (2018) Was spricht gegen Zwei-Klassen-Medizin? ZfWP 67(1):30-41

Bührer C, Fetzer S, Hagist C (2018a) Adverse selection in the German Health Insurance System-the case of civil servants. Working Paper 6. WHU

Bührer C, Fetzer S, Hagist C (2018b) Das Hamburger Beihilfemodell-Ein Vergleich der internen Renditen von GKV und PKV. ZVersWiss 107(1):85-108

Bundesministerium für Gesundheit (BMG) (2020) Zahlen und Fakten zur Pflegeversicherung. Stand: 17.02.2020. https://www.bundesgesundheitsministerium.de/fileadmin/Dateien/3_Downloads/Stati stiken/Pflegeversicherung/Zahlen_und_Fakten/Zahlen_und_Fakten_der_SPV_17.Februar_2020_ barr. pdf. Accessed on 03 Jul 2020

Bundesländer Hamburg, Berlin, Bremen, Schleswig-Holstein (2019). Entschließung des Bundesrates zur Weiterentwicklung der Pflegeversicherung. Antrag. BRDrs. 106/19 vom 01.03.2019

Bundesministerium für Gesundheit (BMG) (2018a) Leistungsansprüche der Versicherten im Jahr 2018 im Überblick. https://www.bundesgesundheitsministerium.de/fileadmin/Dateien/3_Downloads/Stati stiken/Pflegeversicherung/Leistungen/Leistungsbetraege_2018.pdf. Accessed on 04 Oct 2020

Bundesministerium für Gesundheit (BMG) (2018b) Versicherte der gesetzlichen Krankenversicherung (GKV) und der sozialen Pflegeversicherung (SPV) nach Altersgruppen und Geschlecht am 01.07.2018. https://www.bundesgesundheitsministerium.de/fileadmin/Dateien/3_Downloads/Stati stiken/Pflegeversicherung/Versicherte/Versicherte_2018.xls. Accessed on 04 Oct 2020

Bundesministerium für Gesundheit (BMG) (2019a) Finanzentwicklung der sozialen Pflegeversicherung. https://www.bundesgesundheitsministerium.de/fileadmin/Dateien/3_Downloads/Statistiken/Pfleg eversicherung/Finanzentwicklung/Finanzentwicklung-der-sozialen-Pflegeversicherung_2018.xls. Accessed 04 Oct 2020

Bundesministerium für Gesundheit (BMG) (2019b) Leistungsempfänger nach Altersgruppen und Pflegegrade*-Frauen. https://www.bundesgesundheitsministerium.de/fileadmin/Dateien/3_Downl oads/Statistiken/Pflegeversicherung/Leistungsempfaenger/Leistungsempfaenger-nach-Altersgrup pen-und-Pflegegraden-Frauen_02.xls. Accessed 04 Oct 2020

Bundesministerium für Gesundheit (BMG) (2019c) Leistungsempfänger nach Altersgruppen und Pflegegrade-insgesamt. https:/www.bundesgesundheitsministerium.de/fileadmin/Dateien/3_Downl oads/Statistiken/Pflegeversicherung/Leistungsempfaenger/Leistungsempfaenger-nach-Altersgrup pen-und-Pflegegraden-insgesamt.xls. Accessed 04 Oct 2020

Bundesministerium für Gesundheit (BMG) (2019d) Leistungsempfänger nach Altersgruppen und Pflegegrade-Männer. https://www.bundesgesundheitsministerium.de/fileadmin/Dateien/3_Downl oads/Statistiken/Pflegeversicherung/Leistungsempfaenger/Leistungsempfaenger-nach-Altersgrup pen-und-Pflegegraden-Maenner_02.xls. Accessed 04 Oct 2020

Bünnings C, Tauchmann H (2015) Who opts out of the statutory health insurance? A discrete time hazard model for Germany. Health Econ 24(10):1331-1347

Busse R, Blümel M (2014) Germany: health system review. Health Syst Trans 16(2):1-296

Deutsche Aktuarvereinigung (2014) Berücksichtigung der Selektionswirkungin der Erst-und Nachkalkulation in der privaten Krankenversicherung. Fachgrundsatz, DAV-Ausschuss Krankenversicherung

Federal Ministry of Health, Germany (2018) Peer review on "Germany's latest reforms of the long-term care system". Host Country Discussion Paper, European Commission, DG Employment, Social Affairs and Inclusion 
Fuino M, Wagner J (2020) Duration of long-term care: socio-economic factors, type of care interactions and evolution. Insur Math Econ 90:151-168

Gartmann A (2004) Aktualisierung der Sterbetafel für die deutsche Private Krankenversicherung. Blätter DGVFM 26(3):483-500

Germain CM, Vasquez E, Batsis JA, McQuoid DR (2016) Sex, race and age differences in muscle strength and limitations in community dwelling older adults: data from the Health and Retirement Survey (HRS). Arch Gerontol Geriatr 65:98-103

Greß S (2019) Stellungnahme Pflegefinanzierung. Stellungnahme als Einzelsachverständiger für die öffentliche Anhörung im Gesundheitsausschuss des Bundestages am 08.05.2019. BT-Ausschussdrs. 19(14)0074(9). Hochschule Fulda

Grunow M, Nuscheler R (2014) Public and private health insurance in Germany: the ignored risk selection problem. Health Econ 23(6):670-687

Guo J, Konetzka RT, Manning WG (2015) The causal effects of home care use on institutional long-term care utilization and expenditures. Health Econ 24(S1):4-17

Harrington CA, Geraedts M, Heller GV (2002) Germany's long term care insurance model: lessons for the United States. J Public Health Policy 23(1):44-65

Hofmann A, Browne M (2013) One-sided commitment in dynamic insurance contracts: evidence from private health insurance in Germany. J Risk Uncertain 48:81-112

Huang S, Salm M (2020) The effect of a ban on gender-based pricing on risk selection in the German health insurance market. Health Econ 29(1):3-17

Luy M, Wegner-Siegmundt C, Wiedemann A, Spijker J (2015) Life expectancy by education, income and occupation in Germany: estimations using the longitudinal survival method. Comp Popul Stud 40(4):399-436

Neusius T (2017) Trojanisches Pferd oder neue Freiheit? Der Hamburger Vorstoß zur Flexibilisierung der Beihilfe. Z Versicherungswesen 68(18):539

Neusius T (2019) Pflegeversicherung-Ausgleich mit Privatversicherung hilft nicht. Wirtschaftsdienst 99(6):421-424

Neusius T, Pfeil L, Gramenz A (2019) Jenseits der Vollversicherung. Z Versicherungswesen 70(6):180-184

Panthöfer S (2016) Risk selection under public health insurance with Opt- Out. Health Econ 25(9):1163-1181

PKV-Verband (2017) Sterbetafel 2018. https://www.bafin.de/SharedDocs/Downloads/DE/Statistik/PKV/ dl_st_2018_sterbetafel_va.xls. Accessed 04 Oct 2020

Polyakova M (2016) Risk selection and heterogeneous preferences in health insurance markets with a public option. J Health Econ 49:153-168

Rothgang H (2000) Wettbewerb in der Pflegeversicherung. Z Sozialreform 46(5):423-448

Rothgang H (2015) Pflegeversicherung folgt Krankenversicherung"-fundamentale Fehlentscheidung oder zukunftsträchtiges Modell? Soz Fortschritt 1-2:8-14

Rothgang H (2018a) Absicherung des Risikos der Pflegebedürftigkeit. Public Health Forum 26(3):239-242

Rothgang H (2018b) Ausgleich mit Privatversicherung. Wirtschaftsdienst 98(6):380

Rothgang H, Domhoff D (2019) Die Pflegebürgerversicherung als Vollversicherung. Beitragssatz- und Verteilungseffekte bei Umwandlung der Pflegeversicherung in eine Bürgerversicherung mit Vollversicherung. Working Paper Forschungsförderung 150. Hans Böckler Stiftung

Rothgang H, Kalwitzki T (2017) Alternative Ausgestaltung der Pflegeversicherung. Gutachten, Pro-Pflegreform

Rothgang H, Müller R, Unger R (2013) Pflegereport 2013. Gutachten, Barmer

Rothgang H, Müller R, Runte R, Unger R (2017) Pflegereport 2017

Gutachten. Barmer. Sachverständigenrat Gesundheit (Advisory Council on the Assessment of Developments in the Health Care System) (2005) Coordination and quality in the health care system. Report, abridged version

Schulz-Asche K. et al. (2019) Pflege gerecht und stabil finanzieren-Die Pflege- Bürgerversicherung vollenden. Antrag. BT-Drs. 19/8651 vom 20.03.2019. Bündnis 90/Die Grünen (Bundestagsfraktion)

Smith SK, Tayman J, Swanson DA (2002) State and local population projections-methodology and analysis. Kluwer, New York

Statistisches Bundesamt (2018) Verdienste und Arbeitskosten-Arbeitnehmerverdienste. Fachserie 16 Reihe 2.3. https://www.destatis.de/DE/Themen/Arbeit/Verdienste/Verdienste-Verdienstunters 
chiede/Publikationen/Downloads-Verdienste-und-Verdienstunterschiede/arbeitnehmerverdienstejahr-2160230187004.pdf

Statistisches Bundesamt (2019) Sterbetafel 2016/18. https://www-genesis.destatis.de/genesis/online. Accessed 23 Mar 2020

SVRW-Sachverständigenrat zur Begutachtung der gesamtwirtschaftlichen Entwicklung (2017) Für eine zukunftsorientierte Wirtschaftspolitik-Jahresgutachten 2017/18. https://www.sachverstaendig enrat-wirtschaft.de/fileadmin/dateiablage/gutachten/jg201718/JG2017-18_gesamt_Website.pdf. Accessed 09 Dec 2018

SVRW-Sachverständigenrat zur Begutachtung der gesamtwirtschaftlichen Entwicklung (2018). Vor wichtigen wirtschaftspolitischen Weichenstellungen-Jahresgutachten 2018/19. https://www.sachv erstaendigenrat-wirtschaft.de/fileadmin/dateiablage/gutachten/jg201819/JG2018-19_gesamt.pdf. Accessed 22 May 2019

van de Ven WPMM, Ellis RP (2000) Risk adjustment in competitive health plan markets. In: Culyer AJ, Newhouse JP (eds) Newhouse. North Holland, Elsevier, pp 755-845

Verband der Privaten Krankenversicherung e.V. (2019) Zahlenbericht der Privaten Krankenversicherung 2018. https://www.pkv.de/service/zahlen-und-fakten/archiv- pkv-zahlenbericht/zahlenbericht-2018. pdf. Accessed 04 Oct 2020

Weber R (2010) Risikoausgleichsverfahren in der privaten Krankenversicherung. In: Göpffarth D, Greß S, Jacobs K, Wasem J (eds) Jahrbuch Risikostrukturausgleich 2009/2010. Von der Selektion zur Manipulation?. Medhochzwei, Heidelberg, pp 115-133

Zimmermann P et al. (2019) Zwei-Klassen-System in der Pflegeversicherung beenden. Antrag. BT-Drs. 19/7480 vom 31.01.2019. Die Linke (Bundestagsfraktion)

zur Nieden F, Altis A, (2017) Lebenserwartung von Beamtinnen und Beamten. Wirtschaft Stat 2:113-123 